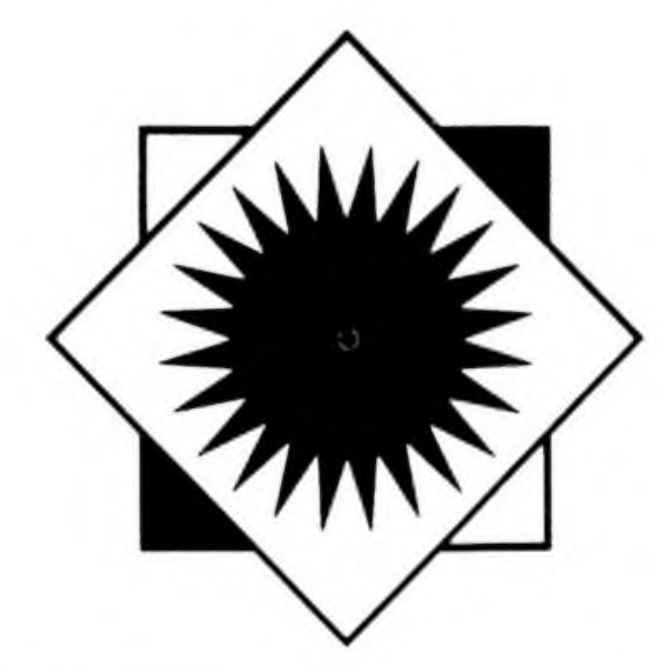

\title{
INNOVATIONS
}

\section{LSM Infomaster: A Hypercard CAI program on a Macintosh network}

\author{
By Martin Kesselman \\ Coordinator of Online and Instructional Services \\ Rutgers University Library of Science and Medicine
}

For several years the Library of Science and Medicine (LSM) of Rutgers University was responsible for teaching a library component of Introduction to Engineering, a required course for all incoming freshman engineering students. These sessions covered the fundamentals of library research in engineering, highlighting resources at LSM. With over 600 students in these classes each Fall, tours and on-site demonstrations of library resources were impractical. Instead, library instruction had unfortunately been relegated to large lecture classes out of the context of the library. LSM librarians observed that, although students attended the required sessions on the library, they faltered when working on their in-library followup assignments.

We felt that a better approach would be a CAI program with graphic scenes of the library. Such a program would allow students to work at their own pace and at a time convenient for them, and through this context-rich introduction, students would learn and retain more about the resources and services of LSM. As a result, the Macintosh computer was chosen for its graphic and easy-touse interface and, at first, World Builder from Silicon Beach, Inc., was selected as an authoring tool. Funding for this program was successfully obtained from a Rutgers University Council for the Improvement of Teaching Award.

World Builder, a program for developing adventure games, was chosen because of its low cost and because it only required a minimal knowledge of programming. It was felt that the adventure game format would allow students to explore LSM on their own without following one particular path. With this program, originally titled LSM Infomaze Master, students would follow a mysterious Ceramics Professor through the library and collect on- screen bookmarks when they had completed specific tasks. Another character, Conan the Librarian, is available to provide clues or assistance. Early on, however, because World Builder was not designed for the use of instruction, we found it difficult to control when the Ceramics Professor or Conan the Librarian would appear or disappear in the program. Another nagging problem was World Builder's weapons menu with the options "swing fist" and "kick foot." We certainly did not want anyone kicking around the librarian!

While thinking about how we could resolve these problems, our new Macintosh Plus computers arrived and, to our good fortune, were bundled with Apple's new Hypercard software. Hypercard was immediately selected as a substitute. After reviewing the goals for our instruction, we completed the new program, LSM Infomaster, in a fairly short time. Since switching over to Hypercard, Silicon Beach has come out with Course Builder, an authoring program based on World Builder, but tailored to instructional purposes.

The LSM Infomaster program currently consists of three "tours." The first tour, Intro Tour, reviews what the program will cover and provides an introduction to the Macintosh interface and the use of a mouse. This tour also provides an instant replay feature for review.

The second tour, LSM Overview Tour, provides digitized photographs and graphics with brief descriptions of LSM resources and service points such as the circulation desk, reference collections, and online searching. When students select any of these resources or services (the order is not important), they are shown a map of the appropriate floor with the resource/service asterisked. They are then asked to select that service on the map and, as a result, are shown a digitized photograph of that 
service with a brief description.

The third tour, Infomaster Main Tour, introduces students to two major information destinations, books and journals, and the advantages and disadvantages of both formats in the sciences. Next, this tour introduces the concept of the research pathway and provides a step-by-step generic approach for students to follow in locating information on a topic. Lastly, students tour through specific pathways for books and journal articles, again with digitized photographs of actual resources and service points of LSM. A follow-up assignment is available in which students can practice what they've learned through an actual library exercise.

LSM Infomaster runs on three Macintosh Plus computers networked together with PhoneNet connections, using MacServe as a disk server on one of the machine's $20 \mathrm{MB}$ hard disk drives. All three computers access copies of the program stored on portions of the same hard disk. The LSM Infomaster programs, known as stacks in Hypercard terms, take up approximately $600 \mathrm{~K}$ of memory. Hypercard programs require at least a Macintosh Plus microcomputer with two $800 \mathrm{~K}$ disk drives, although a hard disk drive is preferred. Up to now, LSM Infomaster has only been available for use on the three computers on the second floor of the library close to the reference desk. Hyper DA, a new Macintosh desk accessory program we recently purchased, should allow our stacks to be viewed and printed on the Macintosh $512 \mathrm{~K}$ machines available at other library and university locations.

Like many other new development projects, LSM Infomaster had a few setbacks and was unfortunately not ready for this past Fall semester's freshman engineering class. Although programming with Hypercard is quick and easy, the program's content and presentation still takes many hours of work. Also, initially we had problems with formatting our hard disk drive with MacServe and the program's co-developer unexpectedly left to go to another university. LSM Infomaster is now up and running and many general users of the library are trying it out and providing much valuable feedback. A more formal evaluation is planned for this coming Fall semester.

Hypercard lends itself to instructional purposes as it is a database management package with many options for linking and searching for information. Additionally, Hypercard utilizes Hypertalk, a sophisticated programming language that is easy to use and can be used effectively without a knowledge of programming. One of the biggest advantages of Hypercard is that it allows students to meander through the program on their own, at a level comfortable for them, and in an order they choose.

Hypercard programs consist of stacks, cards, text fields, and buttons. It is through buttons that one can easily link cards, ideas, and graphics. For designing a new stack Hypercard has two layers, a background layer and a card layer. Fields and but- tons common to cards in a stack can be placed on the background and those that apply to a particular card can be placed on that card only. Connections can be created easily without even using the Hypertalk scripting language directly. For example, when copying and pasting an existing button from the Button Ideas menu or from another card or stack, the button's script is copied as well. This script may be to go to the next card, previous card, first card in the stack, dial the phone, etc.

Another easy method is when selecting a new button and the "link to" option, one just moves to the card to be linked and clicks on "this card" in the dialog box. A script for moving to this card when a user selects that button is automatically created. For presentation ideas, potential developers need only examine the sample stacks that come with $\mathrm{Hy}$ percard or the many stacks already available as freeware or shareware from local users groups and from several online bulletin boards. In fact, many Hypercard stacks can be used as templates, modifying their buttons, fields, and other attributes to meet local needs. Some library-related stacks for communications and small library circulation/cataloging systems are already available through ALUG, the Apple Library Users Group.

Besides buttons, Hypercard's go and find commands provide additional navigational possibilities. Students can easily review where they've been with the "go back" command and go back to any of the last 100 cards viewed, one at a time. With the "go recent" command, reduced views of up to the last 42 cards viewed are displayed and students can select any of these minicards to move directly to that card. If students get lost in a program, they can either click on the Home button or use the "go home" command to get back to Hypercard's home card. The "find" command allows one to search for particular text strings in the stack's text fields.

Good Hypercard programs need to have enough links so that users have several options to locate needed information. But, with too many links, there is a chance users can get easily lost. With LSM Infomaster, in order to keep students on track some of the links are forced, requiring students to follow particular short paths, before continuing on with the program. We also hid the menubar so that, in this program, students do not have the use of the go and find commands and travel through the program entirely with buttons.

To use Hypercard effectively as an instructional tool, basic design ideals must still be adhered to. Although Hypercard is an easy program to work with, the potential developer must still begin with clear instructional goals and a sound content. For those considering Hypercard for instruction, I suggest that you keep the screens simple and try to use buttons and fields consistently. Students can only comprehend a certain amount of information on one card. Too much information on one screen will likely overwhelm students, running the risk that important points will be lost. Instead, more detail 


\section{Specific PATHWAY for Journals.}

\section{Each of the four steps can be clicked ...}

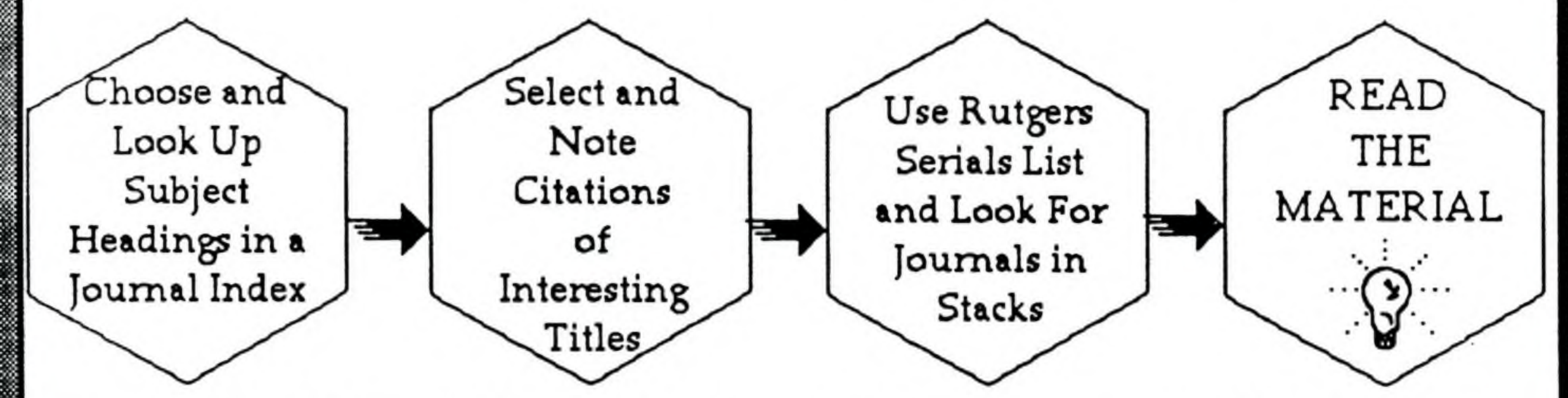

The Specific PATHWAY for finding information in Joumals at LSM often looks like this. Don't be concemed if some of the terms above are unfamiliar to you. Click on each of the steps to leam more about the tools for finding Joumal articles.

\section{LSM Infomaster screen for locating journals.}

should be relegated to additional, possibly optional, screens for those students that wish more information. Graphics should fit in with the text and not distract students from needed information. Potential developers should also determine how students will likely navigate through the program and consider the level of potential users (i.e., Hypercard users, Macintosh users, or first-time users).

Feedback is important, and Hypercard offers possibilities for including sound, animation, visual effects and button highlighting as ways of letting students know they are on the right track. For LSM Infomaster, we took black and white photographs and used a digitizer owned by the Computer Center's Microlab. Digitizers need not be expensive. For future stack development, we are now using Koala Technology's MacVision which, with a lowcost security videocamera, cost approximately $\$ 350$. Another low-cost option (about $\$ 200$ ) is the Thunderscan digitizer which works on an imagewriter printer and, although slow, offers good quality digitizing of photographs.

We also plan to add sound to our stacks with Fallon Computing's new MacRecorder Sound System (about \$150). With MacRecorder, sounds are digitized through a microphone or directly from another source, such as a stereo and can easily be added to a Hypercard script with the "play" command. Simple animation is available within $\mathrm{Hy}-$ percard with the "drag" command, and more sophisticated animation can be produced and added to Hypercard programs with the new Videoworks II software from MacroMind, Inc. Several visual effects are available within Hypercard, many of which are used in the LSM Infomaster program, such as zoom out, iris open, wipe left, barn door close, and venetian blinds.

The greatest promise Hypercard offers for library instruction is that programs can be easily expanded or updated. We are very excited by the fact that LSM Infomaster can be adjusted for library research at LSM in another subject such as psychology or to reflect the library system's forthcoming online catalog. Future enhancements include the production of a series of five-minute modules targeted for general library users that will provide orientation to various LSM services such as government documents, interlibrary loans, and online searching. Many of the screens from LSM Infomaster can be re-used for these programs as well as including links back to parts of LSM Infomaster for those students that would like more in-depth instruction. We are also considering developing, with additional grant funding, a Hypercard CAI/End User Searching Network. In this program, students could go through a Hypercard instructional program to learn about online searching and to get assistance during and after a search. Students would also be able to access services such as BRS After Dark, Knowledge Index, and Silverplatter CD-ROM databases through modems or CD-ROM drives on the network. (Apple's new CD-ROM drive can be used on a network, and Silverplatter will very shortly have all of their CDROM databases available for the Macintosh.)

Hypercard is a remarkable bargain, as it is now 
bundled free with every new Macintosh sold or, for others, costs only $\$ 49$ for four disks and a manual. We are truly excited about Hypercard, not only for its low price, but for its simplicity in use, its ease of creating and programming new stacks, and in tailoring existing stacks to meet local needs.

I wish to thank the Rutgers University Council for the Improvement of Teaching for their general support of this project as well as Sandy Dennis, an engineering student who provided a great deal of programming assistance, and Deanna Nipp, a colleague, who provided much feedback and suggestions concerning the program's content, presentation, and evaluation.

\section{AACR2 rule interpretations}

\author{
by William A. Moffett
}

Director of Libraries
Oberlin College

\section{and Alan D. Boyd}

\author{
Senior Cataloger \\ Oberlin College
}

In the early days of 1982 , just prior to the microcomputer's conquest of library technical services, three Oberlin College catalogers (Lois Lindberg, Alan Boyd, and Elaine Druesedow) attended a local course on mainframe computer text editing. Text editing in the pre-micro age was an unnatural act, a real solution in search of a problem for the non-programmer. But such a problem did confront our catalogers in the wake of AACR2 and the Library of Congress' quarterly batches of new rule interpretations. The Oberlin catalogers decided to exercise their new text editing skills in the preparation of a cumulation of LC's rule interpretations.

It was clear to Lois, Alan, and Elaine that such a publication would be of interest to many other catalogers, and the project was begun with the intent of making copies available to other libraries on a cost-recovery basis. The resultant, seemingly monstrously-proportioned, 100-page cumulation was reproduced in an initial, somewhat timorous run of 50 copies in the summer of 1982. Lacking the requisite patience to allow the professional literature's notice and review functions to build our subscription list, Alan sent an announcement and sample pages to the heads of cataloging of some 600 major academic and public libraries. The response was immediate. Oberlin's looseleaf LCRI service had 300 subscriptions by the time the first set of quarterly update sheets came out in October 1982 and 700 subscriptions by the spring of 1983 .

While the inexorable quarterly publication schedule is challenging for our relatively small department, our word processing and database programs keep the copy production and mailing work for the new 400-page cumulation on the level of a manageable chore. In the past six years one founding editor, Lois, has retired, and one moved on to another library (Elaine still does the close editing of the revised LCRI texts by mail and maintains an exacting level of accuracy). The growth in our list of subscriptions, although not as dizzying as the initial wave, has been steady, and now stands at about 1,200, including most of the major cataloging centers of the United States and Canada, as well as LCRI lovers in Europe, Africa, and Asia.

The wide acceptance of the Oberlin LCRI quarterly updating service even had us feeling a little complacent about our cozy cottage industry when a subscriber's question this spring took us aback: "Is LC taking over your publication?" This wasn't the big bad wolf; however, some very heavy hitting competition had indeed arrived on the scene. The Library of Congress Cataloging Distribution Service has, after seven years of experience in the rule interpretation field, seen fit to bring out its own version of "our" publication. At three times the cost and twice the heft of our publication, LC will still be able to use the clout of the depository system to take over some of our cottage turf. But this government/private sector competition will undoubtedly be beneficial to the faithful LCRI user. We do draw the line, however, at trying to match LC's promise to issue a 3-ring binder with its rule interpretations.

If you buy our Library of Congress Rule Interpretations for AACR2, you get to buy your own binder in your favorite color. It's the Oberlin way.

Alan Boyd and Elaine Druesedow, compilers, Library of Congress Rule Interpretations for AACR2: A Cumulation from Cataloging Service Bulletin Numbers 11-40 (Oberlin, Ohio: Oberlin College Library, 1988), ca. 400p. The cost is $\$ 24$ (additional copies $\$ 21$; price includes quarterly update sheets for CSB no.41-44). Standing orders for CSB no. 45 + accepted any time, from Alan Boyd, Oberlin College Library, Oberlin, OH 44074. 